\title{
Microstructure Analysis of IS2062 Plates Cladded with SS2594 by TIG Welding Process
}

\author{
R. Yokeswaran ${ }^{1, *}$, V. Vijayan ${ }^{1}$, T. Karthikeyan ${ }^{2}$, M. Loganathan ${ }^{3}$ and A. Godwin Antony ${ }^{1}$ \\ ${ }^{1}$ Department of Mechanical Engineering, K. Ramakrishnan College of Technology, Samayapuram, Trichy 621112, Tamil \\ Nadu, India \\ ${ }^{2}$ Department of Mechanical Engineering, Knowledge Institute of Technology, Salem - 637 504, Tamil Nadu, India \\ ${ }^{3}$ Department of Mechanical Engineering, M. Kumarasamy College of Technology, Karur, Tamilnadu 639113, India
}

Corresponding Author Email: yokesys@gmail.com

\begin{abstract}
The power requirement of industries has been growing like anything now-a-days. The components involved in the production of power have also attracted more attention in industrial revolution. The present work focuses on improving the hardness and shear resistance of IS2062 work material used in the manufacturing of fire tubes in thermal power plants. The cladding of surface was carried out by Tungsten Inert Gas (TIG) welding with the use of SS2594 duplex steel as surface coating material. Hardness test results revealed that cladding process have raised the value from 170 to 411. Microstructural analysis has revealed the formation of refined grains at the clad zone due to continuous recrystallization of martensite. It has happened because of higher gas flow rate during welding. Macroscopic analysis has proved the increase in current during the process improved the diffusion of SS2594 material into the base metal IS2062.
\end{abstract}

Keywords: cladding, IS2062 steel, super duplex stainless steel, SS2594, gas metal arc welding, microstructural characteristics, mechanical behaviour

Received: September-29-2020, Accepted: November-26-2020, https://doi.org/10.14447/jnmes.v23i4.a08

\section{INTRODUCTION}

Titanium sheet substrates are enriched by depositing TiC and TiN coating over the surface by providing nitrogen atmosphere during TIG welding process [1]. Based on the microstructure examination, $\mathrm{TiC}$ was observed in the base metal matrix of forms spherical and dendritic nature. The martensite formation on cladded surface had improved the hardness value from 321 to $571 \mathrm{HV}$. Microstructural analysis was carried out on AISI 304 workpiece cladded with WC$10 \mathrm{Co}-4 \mathrm{Cr}$ powders through TIG welding process [2-7]. Fatigue and micro hardness evaluation of samples revealed a small amount of erosion due to pull out of WC presence on the matrix of CoCr. Influential parametric analysis was carried out using RSM and identified welding current on hardness and wear resistance. Mathematical models predict the results were developed with the possibility of error within acceptable limits. Various concentrated $\mathrm{Fe}-\mathrm{TiC}$ powders were used as cladding material to improve surface hardness and wear resistance of plain carbon steel via submerged arc welding [8-11]. Presence of $\mathrm{TiC}$ was confirmed with microstructural studies on all samples. Martensitic microstructure and the highest hardness of $960 \mathrm{HV}$ was obtained for $0.96 \mathrm{wt} \% \mathrm{Ti}$ and $0.51 \mathrm{wt} \%$ cast iron in mixture. The sample with hardest coating showed best wear resistance with ploughing and cutting wear mechanisms. Cladded surface of Q235/304 SS plates with TIG \& MAG hybrid welding proved the excessive diffusion and dilution behaviour of $\mathrm{Cr} \& \mathrm{Ni}$ alloying elements in base metal [12]. Higher hardness was observed due to martensite formation and chromium carbide formed out of migrated $\mathrm{Cr}$ at grain boundaries. The present work aims at understanding the influence of SS2594 material cladded on top of the IS2062 medium carbon steel. The mechanical property of hardness was evaluated to understand the ability of material to withstand high thermal loads. Macrostructure and Microstructural analysis were also carried out to validate the obtained results.

\section{EXPERIMENTAL SETUP}

Present study focuses on testing of medium carbon steel IS6062 for boiler fire tube applications by applying a coating layer of SS2594 on top of it. The operation involved in coating of the layer is called as cladding, which takes place through Tungsten Inert Gas (TIG) welding [2-7]. The TIG welding setup is shown in Figure 1. It consists of argon inert gas environment for covering the weld area. The two parameters considered for the experimentation are welding current and gas flow rate. Taguchi's L9 orthogonal array was used for selecting the number of trials. Based on the literatures studied, the value range of current and gas flow rates were fixed between $80-140 \mathrm{~A}$ and $4-8 \mathrm{lpm}$ respectively.

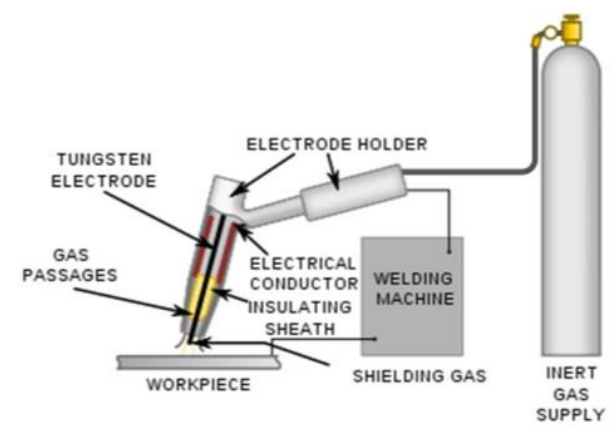

Figure 1. Layout of experimental setup \& welded workpiece 
The SS2594 steel offers very high degree of resistance for inter-granular, pitting and stress corrosions. It is widely used in the welding of alloys expected to have resistance towards corrosion like ship hull, boiler fire tubes, engine casings etc [7,
$13,14]$. In this study, stress corrosion resistance of boiler fire tubes needs to be improved and thereby increase the life cycle of component. The chemical composition of both base and filler material is provided in Table 1.

Table 1. Chemical composition as received

\begin{tabular}{ccccccccccc}
\hline & \multicolumn{10}{c}{ Base material: IS2062 medium carbon steel } \\
\hline Composition & $\mathbf{C}$ & $\mathbf{S i}$ & $\mathbf{M n}$ & $\mathbf{C r}$ & $\mathbf{C u}$ & $\mathbf{P}$ & $\mathbf{S}$ & $\mathbf{N i}$ & $\mathbf{F e}$ \\
Weight \% & 0.260 & 0.272 & 0.686 & 0.144 & 0.176 & 0.055 & 0.039 & 0.034 & Balance \\
& & \multicolumn{1}{c}{ Filler } & material: & SS2594 super & duplex stainless steel & & & \\
Composition & $\mathbf{C}$ & $\mathbf{M n}$ & $\mathbf{S i}$ & $\mathbf{C r}$ & $\mathbf{N i}$ & $\mathbf{M o}$ & $\mathbf{W}$ & $\mathbf{N}$ & $\mathbf{F e}$ \\
Weight \% & 0.025 & 1.2 & 0.6 & 25 & 9 & 3.7 & 0.4 & 0.2 & Balance \\
\hline
\end{tabular}

\section{RESULTS AND DISCUSSION}

Experiments were carried out in the experimental setup shown in Figure 1 along with the welded specimen. The experimental run followed Taguchi's L9 orthogonal array and results were recorded in Table 2. Mechanical property of hardness of the cladded specimen were measured suiting to the application [6, 12, 13, 15].

From the preliminary analysis of results obtained, the weld time keeps reducing with the increase in current value. The hardness values of samples considered are measured from the top of cladding zone till the base material is reached. A complete survey of results has been taken and the average roughness's of cladded zone have been provided in Table 2.

Table 2. Mechanical property results

\begin{tabular}{cccccc}
\hline Sl. No. & A: Current (A) & B: Gas flow rate (lpm) & Welding time (s) & Weld speed (mm/min) & Average clad zone hardness \\
\hline 1 & 80 & 4 & 110 & 38.18 & 240.54 \\
2 & 80 & 6 & 108 & 38.89 & 231.37 \\
3 & 80 & 8 & 106 & 39.62 & 286.47 \\
4 & 110 & 4 & 100 & 42.00 & 238.19 \\
5 & 110 & 6 & 91 & 46.15 & 239.19 \\
6 & 110 & 8 & 86 & 48.84 & 230.88 \\
7 & 140 & 4 & 61 & 68.85 & 411.45 \\
8 & 140 & 6 & 60 & 70.00 & 239.45 \\
9 & 140 & 8 & 56 & 75.00 & 354.32 \\
\hline
\end{tabular}

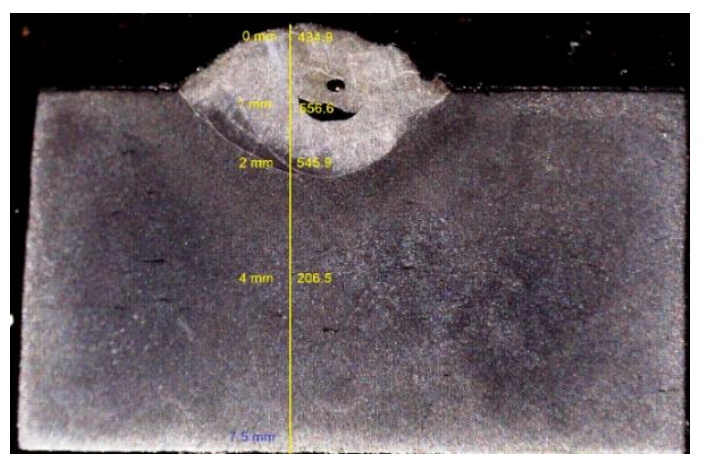

Figure 2. Macroscopic image of sample 7

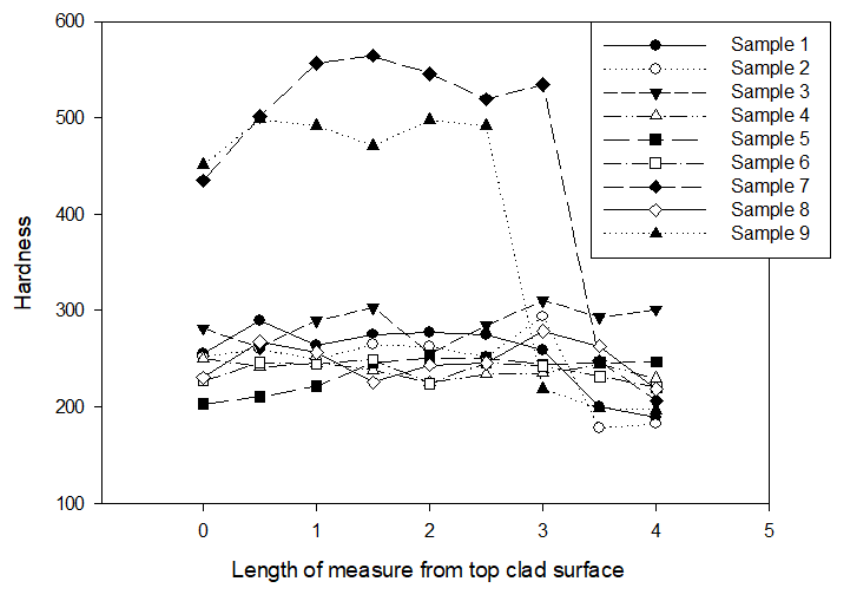

Figure 3. Hardness value of cladded surface
The hardness was surveyed on the specimen from top of cladded surface to the base metal. Average hardness of the clad zone has been taken for consideration of analysis. The hardness value of cladding material diffused into the base metal was taken and the full results were provided in Figure 3. It could be easily observed that the hardness results of sample $7 \& 9$ were higher than all others. High value of current during TIG welding led to sufficient heat generation at surface.

\section{MORPHOLOGICAL ANALYSIS}

\subsection{Microstructural Analysis}

The microscopic analysis of cladded specimen were depicted in Figure 4 with descending order of hardness as Cladded zone > interface > HAZ > Base metal. Based on the results obtained, the base material IS2062 shows uniform grains of pearlite in ferrite along the direction of forming. Upon detailed study of base material away from the processed zone with further magnification, it can be observed there are ferrite with pearlite grain boundaries. When the hardness of Heat Affected Zone (HAZ) is considered, it was little higher than that of the parent metal. It is owing to the effect of temperature induced stress caused during TIG cladding process. The Parent metal was exposed to high heat during the cladding process and HAZ was observed to be very much closer to the coated area. Temperature raised on the parent metal was very slowly removed by lower amount of gas flow rate supplied during process. This uniform lower cooling rate 
has led to the formation of much uniform grains than base material.

The number of average sized grain was finely increased due to the recrystallization of molten grains with higher size and poor heat transfer. Because of increased recrystallization, hardness value of the base metal was risen to 400. The temperature was maintained in the work piece by the application of high current (140 A) in the TIG welding setup. The interface zone at point of cladding shows effective continuous fusion line of cladded SS2594 and IS2062 base material. A distinct layer of fusion zone could be easily seen at interface and free from the presence of shrinkage cavities. The duplex zone at the top shows fine inters dendritic ferrite and austenite forms. The cladded metal side shows fine coring of grains due to higher current. The microstructure of cladded metal shows long primary arms at interface zone. Exactly at the top surface of fusion zone, the cooling was rapid. It resulted in fine gains of crystalized ferrite and austenite. The cladded zone if free of gas porosities owing to the shielding provided by inert argon medium during the process. The cladded metal microstructure shows fine grains of duplex grains of ferrite and austenite. Hardness of the base material has been improved very rapidly to a value around 411.45 due to the high current \& temperature effects at the cladded zone [12].

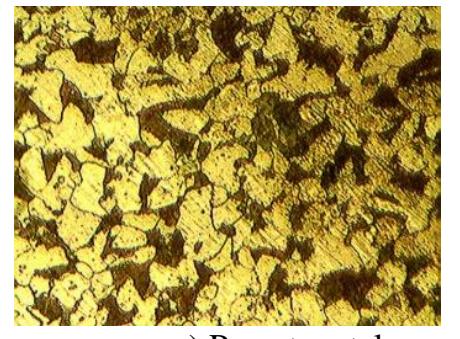

a) Parent metal

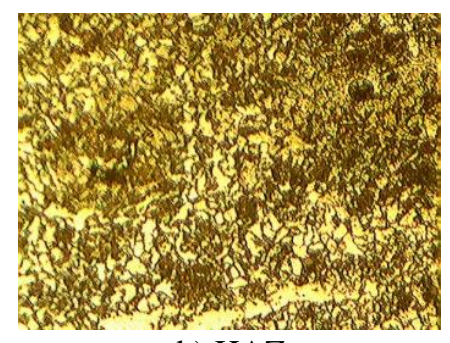

b) HAZ

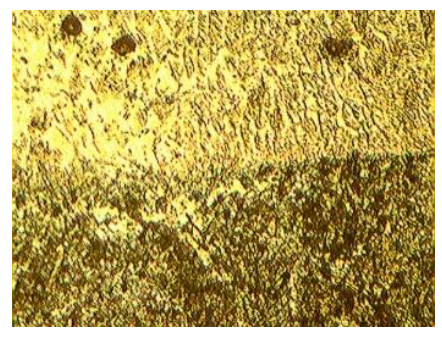

c) Interface

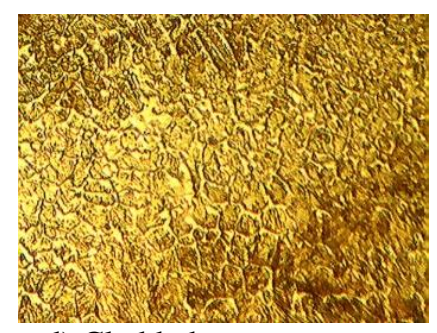

d) Cladded zone

Figure 4. Optical microscopic image of the $7^{\text {th }}$ cladded specimen (a) Parent metal (b) HAZ (c) Interface d) Cladded zone

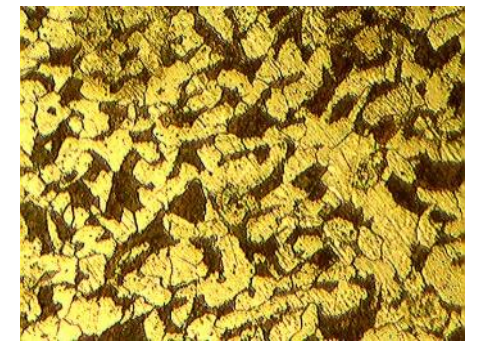

a) Base metal

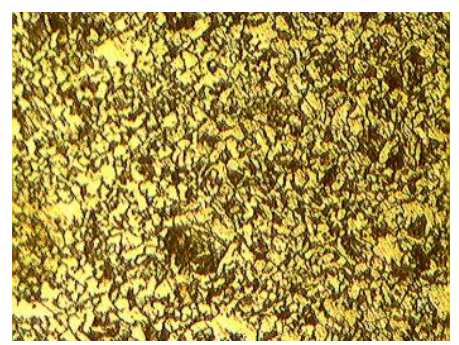

b) HAZ

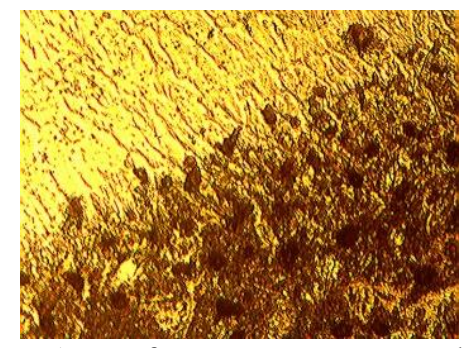

c) Interface

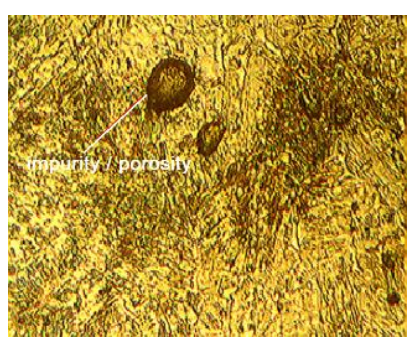

d) Cladded zone

Figure 5. Optical microscopic image of the 9th cladded specimen (a) Base metal (b) HAZ (c) Interface d) Cladded zone

\subsection{Macrostructure study}

Based on the study of macrostructure conducted on the samples, results are provided in Figure 6. It can be understood clearly that the cladding material SS2594 have not entered the base metal structure at low current TIG welding. Despite the flow rate of inert gas, sufficient temperature for melting the top layer of base material was not developed with poor current value. Once the current value increases, the temperature developed was high. Complete diffusion of cladding material into the base metal could be observed whenever the current value is above $100 \mathrm{~A}$. Based on the results of sample $4 \& 7$, blow hole defect shall be observed due to insufficient inert gas shielding (typical flow rate of $4 \mathrm{lpm}$ ). Owing to insufficient shielding, the atmospheric air or even the shielding gas itself has gotten trapped inside the clad zone. This upon cooling will result in gas porosity of cladded zone. However, the cooling rate at lower gas flow was uniform with proper maintenance of temperature gradient. It aids for refining of grain structure through recrystallization of large sized grains and improves hardness value. The $8^{\text {th }}$ sample has an even diffusion structure in macroscopic analysis with proper bead geometry as well. The hardness of this sample was lower than $7^{\text {th }}$ sample, because of increased cooling rate caused by $6 \mathrm{lpm}$ of inert medium. 


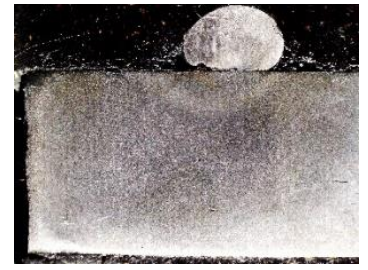

Sample 1

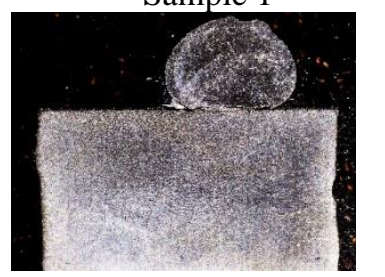

Sample 3

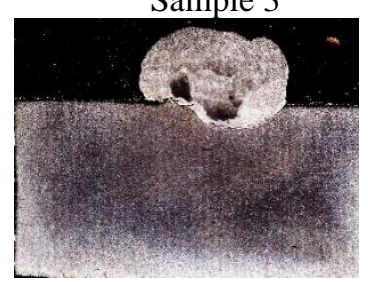

Sample 5

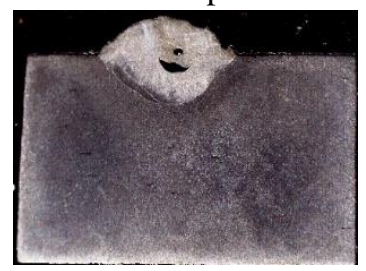

Sample 7

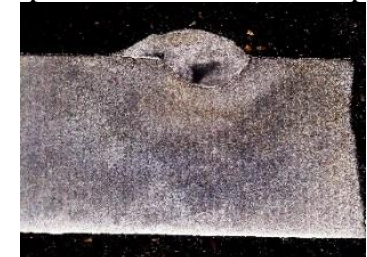

Sample 9

Figure 6. Macro structure of the sample

\section{CONCLUSION}

- By the help of Tungsten inert gas welding process, the surface property of medium carbon steel IS2062 was modified with SS2594 duplex stainless steel. The cladding process was carried out following Taguchi's L9 orthogonal array approach and cladded surfaces were created.

- They were analyzed for hardness in depth direction and microstructure of modified surface. The higher strength was required for the application of fire tubes in boilers.

- Based on the results obtained, higher hardness was achieved when the welding current was at maximum with lower inert gas medium.

- The cooling rate was gradual throughout the depth due to lower convective heat transfer by argon gas. Hence large number of nucleation was achieved resulting in fine grain structure in the cladded zone.

- Recrystallization of martensite structure inside the base metal has resulted for higher hardness and wear resistance at high temperature. Descending order of hardness as Cladded zone $>$ interface $>$ HAZ $>$ Base metal.
- The metal is free from large cavities, discontinuity and gas porosity at interface zone. The average cladded material hardness was observed to be 354.32 , having a maximum value of 498.1 just $2 \mathrm{~mm}$ below the top surface of cladding metal deposition.

- The cooling rate at lower gas flow rate was uniform with proper maintenance of temperature gradient which aided for refining of grain structure.

\section{REFERENCES}

[1] Kokabi, A.H., Allahyari, A.A. (2019). Investigation on the wear properties of $\mathrm{Ti} / \mathrm{TiC} / \mathrm{TiN}$ composite coatings prepared by powder cored wires through TIG method at nitrogen atmosphere on titanium substrate. Materials Research, 22(2): 1-9. http://dx.doi.org/10.1590/19805373-mr-2018-0608

[2] Toozandehjani, M., Ostovan, F., Shafiei, E., Jamaludin, K.R., Amrin, A., Hasanzadeh, E. (2020). Surface treatment of Al7075 Matrix by TiC particles via hybrid ball milling and tungsten inert gas cladding. Metall Ital., 2020: 21-30.

[3] Singh, J., Thakur, L.,Angra, S. (2019). Effect of argon flow rate and standoff distance on the microstructure and wear behaviour of WC-CoCr TIG cladding. In Journal of Physics: Conference Series, 1240: 012162. https://doi.org/10.1088/1742-6596/1240/1/012162

[4] Singh, J., Thakur, L., Angra, S. (2020). A study of tribological behaviour and optimization of WC-10Co$4 \mathrm{Cr}$ Cladding. Surface Engineering, 1-10. https://doi.org/10.1080/02670844.2020.1745367

[5] Singh, J., Thakur, L., Angra, S. (2020). An investigation on the parameter optimization and abrasive wear behaviour of nanostructured WC-10Co-4Cr TIG weld cladding. Surface and Coatings Technology, 386: 125474. https://doi.org/10.1016/j.surfcoat.2020.125474

[6] Singh, J., Thakur, L., Angra, S. (2020). Abrasive wear behavior of WC-10Co-4Cr cladding deposited by TIG welding process. International Journal of Refractory Metals and Hard Materials, 88: 105198. https://doi.org/10.1016/j.ijrmhm.2020.105198

[7] Fesharaki, M.N., Shoja-Razavi, R., Mansouri, H.A., Jamali, H. (2019). Evaluation of the hot corrosion behavior of Inconel 625 coatings on the Inconel 738 substrate by laser and TIG cladding techniques. Optics \& Laser Technology, 111: 744-753. https://doi.org/10.1016/j.optlastec.2018.09.011

[8] Loganathan, M., Dinesh, S., Vijayan, V., Ranjithkumar, M., Rajkumar, S. (2020). Experimental Investigation of Tensile Strength of Fiber Reinforced Polyester by Using Chicken Feather Fiber. Journal of New Materials for Electrochemical Systems, 23(1): 40-44. https://doi.org/10.14447/jnmes.v23i1.a08

[9] Rajkumar, T., Raja, K., Lingadurai, K., Vetrivel, S.D., Antony, A.G. (2020). Interfacial Microstructure Analysis of AA2024 Welded Joints by Friction Stir Welding Interfacial Microstructure Analysis of AA2024 Welded Joints by Friction Stir Welding. Journal of New Materials for Electrochemical Systems, 23(2): 123-132. https://doi.org/10.14447/jnmes.v23i2.a09

[10] Yokeswaran, R., Vijayan, V., Karthikeyan, T., Kumar, B. S., Kumar, G.S. (2019). Comprehensive Analysis of Surface Modification Process Parameters by Using Tungsten Inert Gas Welding Process Comprehensive 
Analysis of Surface Modification Process Parameters by Using Tungsten Inert Gas Welding Process. Journal of New Materials for Electrochemical Systems, 22(1): 4549. https://doi.org/10.14447/jnmes.v22i1.a08

[11] Loganathan, M., Dinesh, S., Vijayan, V., Karuppusamy, T., Rajkumar, S. (2020). Investigation of Mechanical Behaviour on Composites of Al6063 Alloy with Silicon, Graphite and Fly Ash. Journal of New Materials for Electrochemical Systems, 23(1): 36-39. https://doi.org/10.14447/jnmes.v23i1.a03

[12] An, Q., Fan, K.Y., Ge, Y.F., Liu, B.X., Liu, Y.C., Wang, S., Chen, C.X., Ji, P.G., Yin, F. X. (2020). Microstructure and mechanical properties of stainless steel clad plate joints produced by TIG and MAG hybrid welding. Journal of Adhesion Science and Technology, 34(6): 670-685.

https://doi.org/10.1080/01694243.2019.1677087
[13] Evangeline, A., Sathiya, P. (2019). Dissimilar Cladding of Ni-Cr-Mo Superalloy over 316L Austenitic Stainless Steel: Morphologies and Mechanical Properties. Metals and Materials International, 1-18. https://doi.org/10.1007/s12540-019-00440-x

[14] Evangeline, A., Sathiya, P., Arivazhagan, B. (2020). Laves Phase Formation and Segregation of $\mathrm{Nb}$ in $\mathrm{Ni}-\mathrm{Cr}-$ Mo Superalloy over 316L by Hot Wire (HW) TIG Cladding Process. Arabian Journal for Science and Engineering, $\quad 45:$ 9685-9698. https://doi.org/10.1007/s13369-020-04873-0

[15] Kumar, A., Batham, H., Das, A.K. (2020). Microhardness of Fe-TiB2 composite coating on AISI 304 stainless steel by TIG coating technique. Materials Today: Proceedings. 